\title{
Roughing of Thick, Coarse-grained High-temperature-processing Steels Processed via Compact Strip Production
}

\author{
Kevin Mark BANKS, ${ }^{*}$ Alison Susan TULING and Dannis Rorisang Nkarapa MAUBANE \\ University of Pretoria, Private Bag X20, Hatfield, 0028 South Africa. \\ (Received on March 3, 2017; accepted on May 25, 2017)
}

\begin{abstract}
The roughing conditions required to avoid local heterogeneous regions in the final microstructure of high temperature processing (HTP) Nb linepipe steels have been investigated for quasi-compact strip production (CSP) conditions. The influence of strain sequence, rolling temperatures and $\mathrm{Mn}$ content on recrystallisation and carbonitride precipitation before and after roughing were studied using laboratory simulation, mathematical modelling and transmission electron microscopy. The roughing conditions necessary to avoid the formation of local heterogeneous regions have been established for HTP steels with an initial grain size of $850 \mu \mathrm{m}$. Low $\mathrm{Mn} \mathrm{Nb-Ti} \mathrm{steels} \mathrm{experience} \mathrm{more} \mathrm{sluggish} \mathrm{recrystallisation} \mathrm{kinetics} \mathrm{and} \mathrm{are}$ more vulnerable to forming local heterogeneous regions during roughing. To prevent local heterogeneous regions if finishing commences at $900^{\circ} \mathrm{C}$, sufficient effective strain is necessary to produce a bulk softened fraction of at least 0.55 in each of the first two roughing passes. If finishing commences at $1000^{\circ} \mathrm{C}$, slow air cooling from roughing provides additional time for recrystallisation to go to completion and so prevent the occurrence of local heterogeneous regions. Maintaining the strand temperature as high as possible prior to the commencement of roughing encourages recrystallisation. A roughing start temperature of $1100^{\circ} \mathrm{C}$, as opposed to $1075^{\circ} \mathrm{C}$, significantly reduces the risk of forming local heterogeneous regions. For the conditions tested, no correlation between softening fraction and carbonitride precipitate characteristics was found. Thus, the influence of $\mathrm{Nb}$ on austenite recrystallisation is expected to be due to either solute drag or solute clustering.
\end{abstract}

KEY WORDS: CSP; roughing; niobium; manganese; recrystallisation; precipitation; local heterogeneous regions.

\section{Introduction}

Local heterogeneous regions are hard, elongated regions in the final ferrite-pearlite microstructure of microalloyed steels which form during cooling from coarse, unrecrystallised austenite. They are a result of steel composition (mainly $\mathrm{Nb}$ and $\mathrm{C}$ ) and inadequate thermomechanical processing during high temperature processing, i.e., small strains, too low roughing temperatures and short inter-pass times. ${ }^{1-5)}$ If present in sufficient quantities, local heterogeneous regions can impair toughness. ${ }^{4)} \mathrm{Nb}$ microalloyed steels are most sensitive to this behaviour because of strong solute drag and $\mathrm{Nb}(\mathrm{C}, \mathrm{N})$ precipitation effects capable of retarding static recrystallisation during initial rolling. ${ }^{4)}$ Thus, in CSP, two distinct objectives must be met when defining rolling schedules: i) elimination of the coarse initial grains and local heterogeneous regions during and immediately after roughing through recrystallisation and ii) once achieved, obtain a pancaked austenite microstructure during finishing which is saturated with dislocations prior to transformation. These aims are more challenging in the production of thick skelp since the total applied reduction is limited.

\footnotetext{
* Corresponding author: E-mail: kevin.banks@up.ac.za

DOI: http://dx.doi.org/10.2355/isijinternational.ISIJINT-2017-105
}

The concept of low $\mathrm{Mn}$ additions to high $\mathrm{Nb}-\mathrm{Ti}$ sour service HTP linepipe steels has recently been introduced to improve centreline segregation and inclusion shape control. ${ }^{6)}$ For a given base chemistry and at sufficiently low temperatures, high $\mathrm{Nb}$ contents provide a large supersaturation and chemical driving force for fine precipitation to effectively retard the austenite recrystallisation kinetics via grain boundary pinning. ${ }^{4)}$ In addition, Akben et al. ${ }^{7)}$ reported that for a given $\mathrm{Nb}$ content, low Mn (also Mo, V) contents retard recrystallisation. At finishing temperatures, low Mn contents accelerate strain-induced precipitation of $\mathrm{Nb}$ and restrict grain boundary movement, ${ }^{8)}$ thereby increasing the so-called no-recrystallisation temperature, $T_{\mathrm{NR}}$, and promotes austenite grain pancaking. Although $\mathrm{Nb}(\mathrm{C}, \mathrm{N})$ precipitation may occur at higher, roughing temperatures in these steels, the particles may be too coarse for effective grain boundary pinning and reduce the solute content which accelerate recrystallisation. However, the influence of $\mathrm{Mn}$ content and $\mathrm{Nb}$ carbonitride precipitation on recrystallisation kinetics in the high temperature austenite region of these steels under CSP (coarse-grained) conditions have not been quantified. This work aims to i) determine the effect of precipitation on recrystallisation in the roughing stage of CSP and ii) quantify, through the use of physical simulation and mathematical models, the required roughing conditions 
to produce a microstructure free of local heterogeneous regions in both high and low Mn HTP steels.

\section{Experimental and Modelling}

\subsection{Physical Simulation}

Table 1 shows the chemistry of two HTP steels investigated: a conventional high $\mathrm{Mn}$, - high $\mathrm{Nb}$ grade, $H M n$, and a low Mn - high Nb steel $L M n$, with the as received microstructures in Fig. 1. Figure 2 details rolling schedules A-C
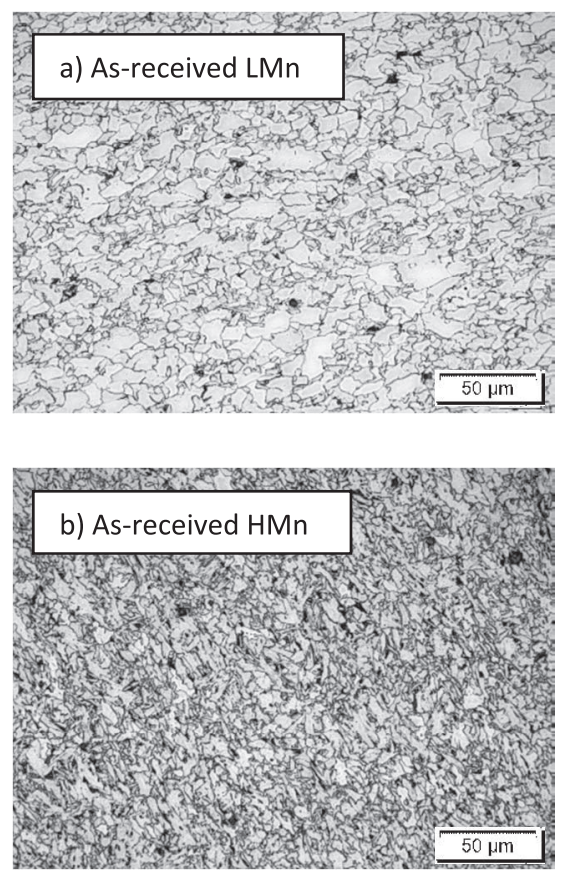

Fig. 1. As-received microstructures of a) LMn and b) HMn steels produced via CCR.

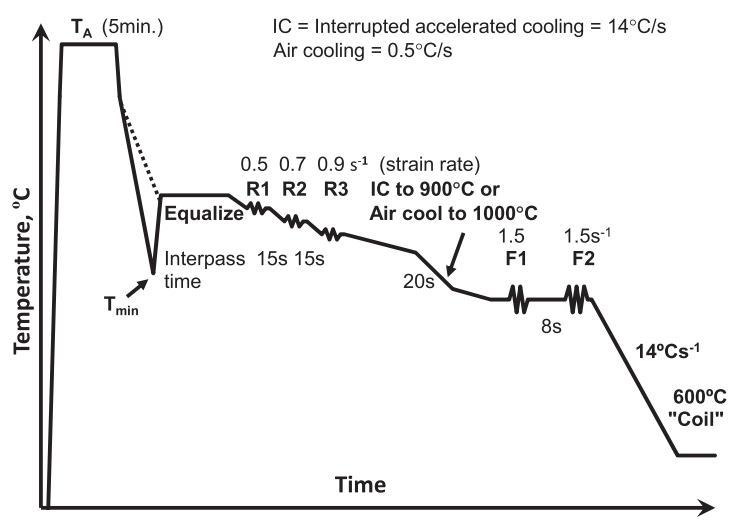

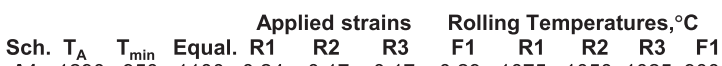
$\begin{array}{lllllllllll}\text { A1: } 1290 & 950 & 1100 & 0.24 & 0.17 & 0.17 & 0.29 & 1075 & 1050 & 1025 & 900\end{array}$

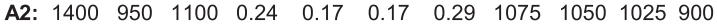

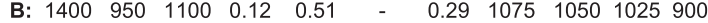

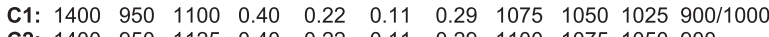

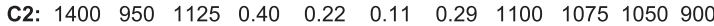

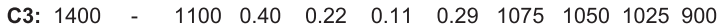

Fig. 2. Schematic of CSP simulations. that were performed in a Bahr $805 \mathrm{D}$ deformation dilatometer under quasi-CSP conditions through soaking at $1400^{\circ} \mathrm{C}$ to produce an average initial grain size, $d_{0}$, of $850 \mu \mathrm{m} .{ }^{1-3)}$ The soaking temperature was decreased in schedule A1 to establish the influence of initial condition on local heterogeneous regions, i.e., cold-charge rolling $(\mathrm{CCR})$ at $1290^{\circ} \mathrm{C}$ to produce a $d_{0}$ of $125 \mu \mathrm{m} .{ }^{1-3)}$ In schedule $\mathrm{C}$, the roughing start temperature was varied between $1075^{\circ} \mathrm{C}(\mathrm{C} 1)$ and $1100^{\circ} \mathrm{C}$ (C2). All tests included an initial cool into the lower austenite region $\left(T_{\min }\right)$, except in schedule $\mathrm{C} 3$, where cooling was applied directly to the equalising furnace temperature $\left(1100^{\circ} \mathrm{C}\right)$. Intermediate accelerated cooling was applied at $14^{\circ} \mathrm{Cs}^{-1}$ when the finishing entry temperature, $\mathrm{F} 1$, was $900^{\circ} \mathrm{C}$, whilst an air cooling rate $\left(0.5^{\circ} \mathrm{Cs}^{-1}\right)$ was applied when $\mathrm{F} 1$ was $1000^{\circ} \mathrm{C}$. After deformation, specimens were accelerated cooled to $600^{\circ} \mathrm{C}$ and held for $5 \mathrm{~min}$. to finally examine the "as-coiled" microstructure using a $2 \%$ nital solution. The measured softened (i.e., recovery and recrystallisation) fraction, $X_{\mathrm{M}}$, between passes was determined from the resulting flow curves using the $0.2 \%$ offset method.

To follow the precipitation evolution in the early stages of processing, additional specimens were quenched directly after i) $T_{\min }$, ii) equalizing at $1100^{\circ} \mathrm{C}$, iii) pass $\mathrm{R} 1$ and iv) $\mathrm{R} 3$, from which carbon extraction replicas were prepared for analytical TEM. The diameters, $d_{p}$, of more than 140 particles were measured in each population, while the particle density was estimated from the nearest neighbour distance, $L$. Plate-like eutectic precipitation of $\mathrm{Nb}$, which had a limited presence, was ignored for $L$ and $d_{p}$ measurements.

\subsection{Recrystallisation Model}

Table 2 is a collection of isothermal equations that describe the evolution of coarse-grained austenite in $\mathrm{Nb}-\mathrm{Ti}$ steels which were employed here: $d_{0}, \varepsilon_{\text {eff }}, \dot{\varepsilon}, t$ and $T$ are the initial austenite grain size, effective von Mises strain that includes any accumulation from previous passes, average strain rate, inter-pass time and pass temperature respectively. For simplicity, where non-isothermal conditions prevailed, i.e., between passes, the average temperature was used. If $\varepsilon_{\text {eff }}$ exceeded the critical strain for dynamic recrystallisation, $\varepsilon_{\mathrm{c}}$, then the metadynamic recrystallisation, MDRX, equations were applied. Static recrystallization (SRX) however, was the dominant softening mechanism. The constant $C$ in Eq. (2) is quoted as $9.92 \times 10^{-11} \mathrm{~s}$ but was later modified based on the results found here. The model includes the effect of solute $\mathrm{Nb}$ and $\mathrm{Ti}$ on recrystallization kinetics but not $\mathrm{Mn}, \mathrm{Si}, \mathrm{V}$ and Mo which are known to affect the rate of softening processes. ${ }^{7)}$ The equilibrium solute contents in multi-component austenite at the equalising temperature was calculated using Thermocalc ${ }^{\circledR}$ and, considering that cooling retards precipitation, were assumed constant during roughing.

Table 1. Composition of steels studied - mass $\%(\mathrm{~V}<0.001 \%$, Mo $<0.01 \%)$.

\begin{tabular}{ccccccccccccc}
\hline Steel & $\mathrm{C}$ & $\mathrm{Mn}$ & $\mathrm{Si}$ & $\mathrm{Nb}$ & $\mathrm{Ti}$ & $\mathrm{Cr}$ & $\mathrm{Ni}$ & $\mathrm{Cu}$ & $\mathrm{P}$ & $\mathrm{Al}$ & $\mathrm{N}$ & $\mathrm{S}$ \\
\hline$H M n$ & 0.050 & 1.59 & 0.16 & 0.099 & 0.010 & 0.24 & 0.11 & 0.22 & 0.019 & 0.039 & 0.0039 & 0.0080 \\
$L M n$ & 0.054 & 0.25 & 0.16 & 0.088 & 0.010 & 0.48 & 0.16 & 0.29 & 0.016 & 0.033 & 0.0032 & 0.0001 \\
\hline
\end{tabular}


Table 2. Equations describing austenite evolution in $\mathrm{Nb}-\mathrm{Ti}$ steels.

\begin{tabular}{|c|c|c|c|}
\hline Variable, pass i & Ref & Equation & Eq. \\
\hline Critical strain for DRX & 10 & $\varepsilon_{\mathrm{c}}=0.0016(1+20[\mathrm{Nb}]+0.02[\mathrm{Ti}]) \mathrm{d}_{0}^{0.147} \mathrm{Z}^{0.155}, \quad \mathrm{Z}=\dot{\varepsilon} \exp \left(\frac{325000}{\mathrm{RT}}\right)$ & 1 \\
\hline Time for $50 \%$ SRX & 9 & $\mathrm{t}_{0.5 \mathrm{SRX}}=\mathrm{Cd}_{0} \varepsilon_{\text {eff }}^{-5.6 \mathrm{~d}_{0}^{-0.15}} \dot{\varepsilon}^{-0.53} \exp \left(\frac{180000}{\mathrm{RT}}\right) \exp \left(\left(\frac{275000}{\mathrm{~T}}-185\right)([\mathrm{Nb}]+0.374[\mathrm{Ti}])\right)$ & 2 \\
\hline Time for $50 \%$ MDRX & 10 & $\mathrm{t}_{0.5 \mathrm{MDRX}}=1.77 \times 10^{-6} \dot{\varepsilon}^{-0.62} \exp \left(\frac{153000}{\mathrm{RT}}\right)$ & 3 \\
\hline SRX grain size & 11 & $\mathrm{~d}_{\mathrm{SRX}}=1.4 \mathrm{~d}_{0}^{0.56} \varepsilon_{\text {eff }}^{-1}$ & 4 \\
\hline MDRX grain size & 12 & $\mathrm{~d}_{\mathrm{MDRX}}=1370\left(\dot{\varepsilon} \exp \left(\frac{375000}{R T}\right)\right)^{-0.13}$ & 5 \\
\hline Mean $d_{\text {rex }}$ & 13 & $d_{r e x, i}=d_{r, S R X} \cdot X_{S R X}+d_{r, M D R X} \cdot X_{\text {MDRX }} \quad$ with $d_{r, S R X, M D R X}=d_{\text {SRX,MDRX }} \cdot X_{S R X, M D R X}^{1 / 3}$ & 6 \\
\hline Mean incoming grain size & 14 & $\mathrm{~d}_{0, \mathrm{i}}=\mathrm{d}_{\mathrm{rex}, \mathrm{i}} \mathrm{X}_{\mathrm{i}}^{4 / 3}+\mathrm{d}_{0, \mathrm{i}-1}\left(1-\mathrm{X}_{\mathrm{i}}\right)^{2}$ & 7 \\
\hline Fraction recrystallised & 10 & $\mathrm{X}=\mathrm{X}_{\mathrm{SRX}}+\mathrm{X}_{\mathrm{MDRX}}, \quad \mathrm{X}_{\mathrm{SRX}, \mathrm{MDRX}},=\mathrm{f}_{\mathrm{MDRX}, \mathrm{SRX}}\left\{1-\exp \left[-0.693\left(\frac{\mathrm{t}}{\mathrm{t}_{0.5 \mathrm{SRX}, \mathrm{MDRX}}}\right)\right]\right\}$ & 8 \\
\hline Contributed fraction & 10 & $\mathrm{f}_{\mathrm{MDRX}}=\frac{\varepsilon_{\text {eff }}-\varepsilon_{\mathrm{c}}}{1.2}, \quad \mathrm{f}_{\mathrm{SRX}}=1-\mathrm{f}_{\mathrm{MDRX}}$ & 9 \\
\hline Effective strain & 14 & $\varepsilon_{\text {eff }, i}=\varepsilon_{i}+\left(1-X_{i-1}\right) \varepsilon_{i-1}$ & 10 \\
\hline
\end{tabular}

\section{Results}

\subsection{Bahr Deformation Dilatometer CSP Simulations}

The flow curves and $X_{\mathrm{M}}$ values after each pass are plotted in Fig. 3 for all schedules that included an F1 temperature of $900^{\circ} \mathrm{C}$. Figure $3(\mathrm{a})$ are results from CCR simulations and Figs. 3(b)-3(f) are for CSP tests. The predicted softened fraction, $X_{\mathrm{C}}$, and average incoming grain size, $d_{0}$, i, after pass $i$ are also shown and discussed in section 4.3. The corresponding "as-coiled" microstructures resulting from the simulations in Fig. 3 are shown in Fig. 4, where the $H M n$ steel generally displayed a finer microstructure due to its lower transformation temperature. ${ }^{2)}$ Regions considered to be "local heterogeneous regions" are elongated regions which differ considerably in aspect ratio from the matrix. A SEM micrograph of a typical local heterogeneous region in $L M n$ steel is shown in Fig. 5. Two types of local heterogeneous region morphology were identified: fine ferritic and bainitic. Figures 6 and 7 show the thermomechanical behaviour and resulting microstructure for an $\mathrm{F} 1$ of $1000^{\circ} \mathrm{C}$ in schedule $\mathrm{C} 1$. The general observations in Figs. 3-7 are:

- The LMn steel matrix consisted of mixed, coarse polygonal ferrite with little or no pearlite. Local heterogeneous regions in the $L M n$ grade were either very fine, elongated ferrite or low carbon bainite. The $H M n$ matrix was fine ferrite with $5 \%$ pearlite and, where present, the local heterogeneous regions contained relatively coarse, acicular ferrite-pearlite.

- No local heterogeneous regions were observed in the microstructure when $X_{\mathrm{M}}$ exceeded 0.55 in the first (R1) roughing pass and at least one subsequent pass. The calculated grain size entering pass R2, $d_{0,2}$ was always below about 200-220 $\mu \mathrm{m}$ in local heterogeneous region-free specimens.

- $X_{\mathrm{M}}$ was mostly lower in the $L M n$ steel for a given roll- ing schedule suggesting more sluggish recrystallisation compared to $H M n$.

- The local heterogeneous regions were similar to the matrix morphology in the HMn steel. The morphology of local heterogeneous regions in the $L M n$ steel was distinctly different to its matrix and very elongated.

In CCR schedule A1, $X_{\mathrm{M}}$ values above 0.55 were obtained after passes R1 and R2 with no evidence of local heterogeneous regions, Fig. 4(a). The $d_{0,2}$ was $45 \mu \mathrm{m}$. In CSP schedule A2, the small applied strains in R1 and R2 resulted in $X_{\mathrm{M}}$ below 0.55 in all passes except $\mathrm{R} 2$ and large local heterogeneous regions were observed in both steels, Fig. 4(b). In schedule B, a small reduction in $\mathrm{R} 1$, followed by a large strain in R2 (applied strain of 0.51 and accumulated strain from R1) was sufficient to initiate MDRX (confirmed by the presence of a peak stress), but was unsuccessful in avoiding local heterogeneous regions, Fig. 4(c). The $d_{0,2}$ in these two schedules was very coarse -500 to $800 \mu \mathrm{m}$. The roughing strain sequence in schedule $\mathrm{C} 1$ commencing at $1075^{\circ} \mathrm{C}$ resulted in an $X_{\mathrm{M}}$ just below 0.55 and a $d_{0,2}$ of $223 \mu \mathrm{m}$. Local heterogeneous regions were more prominent in $L M n$ grade than in HMn, Fig. 4(d). Local heterogeneous regions were eliminated in both steels i) when roughing temperatures were increased by $25^{\circ} \mathrm{C}$ in schedule C2, Fig. 4(e) and ii) when cooling was applied directly to the equalising temperature in schedule $\mathrm{C} 3$ as opposed to initially cooling to $T_{\min }$ (Fig. 2), despite deformation commencing at $1075^{\circ} \mathrm{C}$, Fig. 4(f). The $d_{0,2}$ was 129 and $146 \mu \mathrm{m}$ in schedules $\mathrm{C} 2$ and C3 respectively.

Raising the $\mathrm{F} 1$ temperature to $1000^{\circ} \mathrm{C}$ following a slow air cool from the end of roughing had a positive effect in eliminating local heterogeneous regions in both grades, Figs. 6-7, indicating that high $X_{\mathrm{M}}$ values in subsequent passes, even as late as F1, assist in the elimination of local heterogeneous regions. The $L M n$ steel matrix was similar 

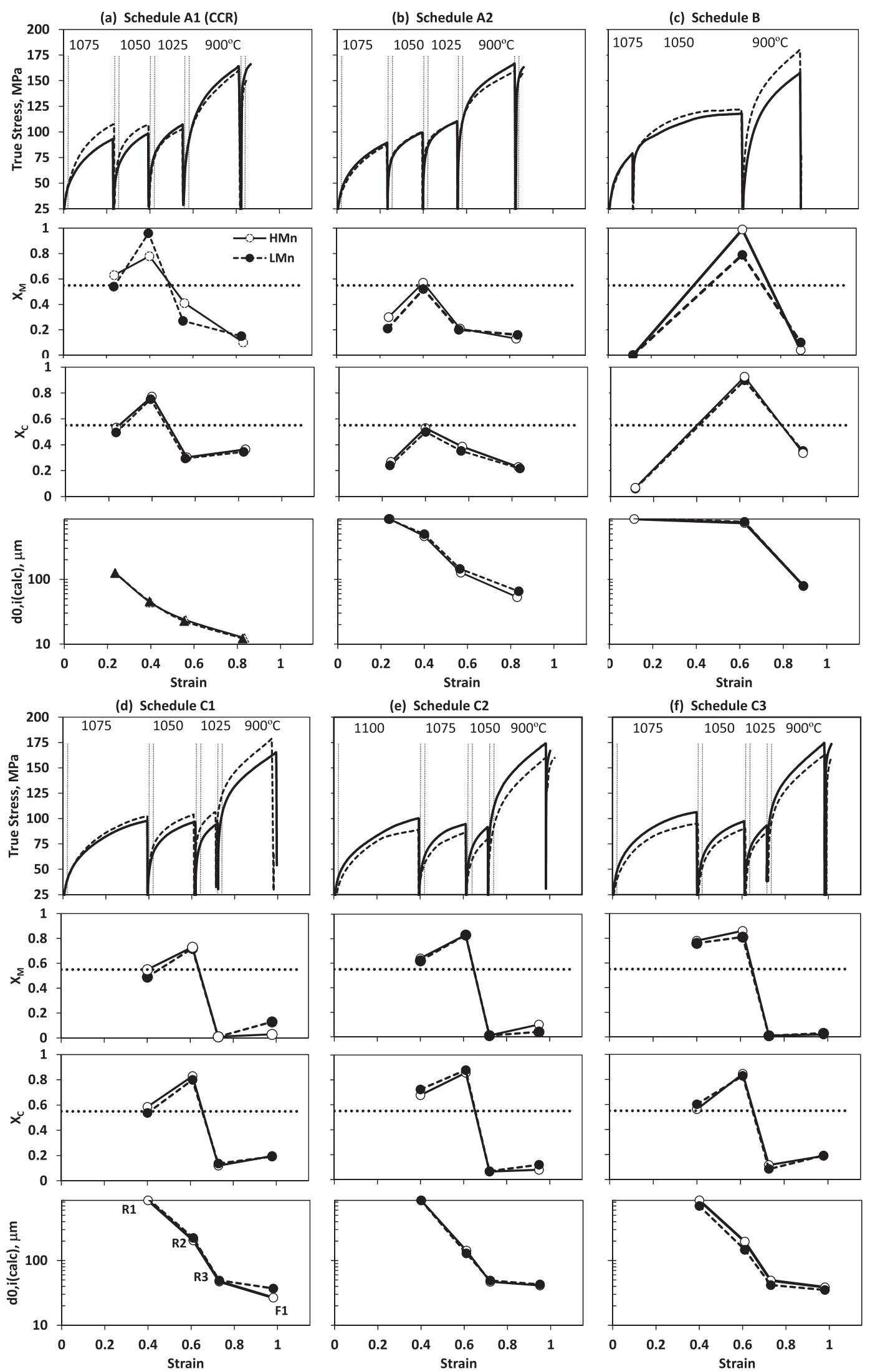

Fig. 3. Flow curves, $X$ and $d_{0, i}$ in schedules A-C for $\mathrm{F} 1=900^{\circ} \mathrm{C}$. All schedules were subjected to a "chill" to $T_{\min }$ $\left(950^{\circ} \mathrm{C}\right)$, except in $\mathrm{C} 3$ where specimens were cooled directly to the equalising temperature of $1100^{\circ} \mathrm{C}$.

to that found at the lower F1 temperature, Fig. 4(d), but the $H M n$ grade was somewhat coarser at the higher F1 temperature. The $d_{0,2}$ was $204 \mu \mathrm{m}$.

\subsection{Recrystallisation Model}

The $\mathrm{Nb}$ and $\mathrm{Ti}$ solute contents in $0.09 \% \mathrm{Nb}-0.01 \mathrm{Ti}$ steel, calculated from Thermocalc ${ }^{\circledR}$, are shown in Fig. 8 for Mn contents of $0.25 \%$ and $1.6 \%$. The $[\mathrm{Nb}]$ for both chemistries 

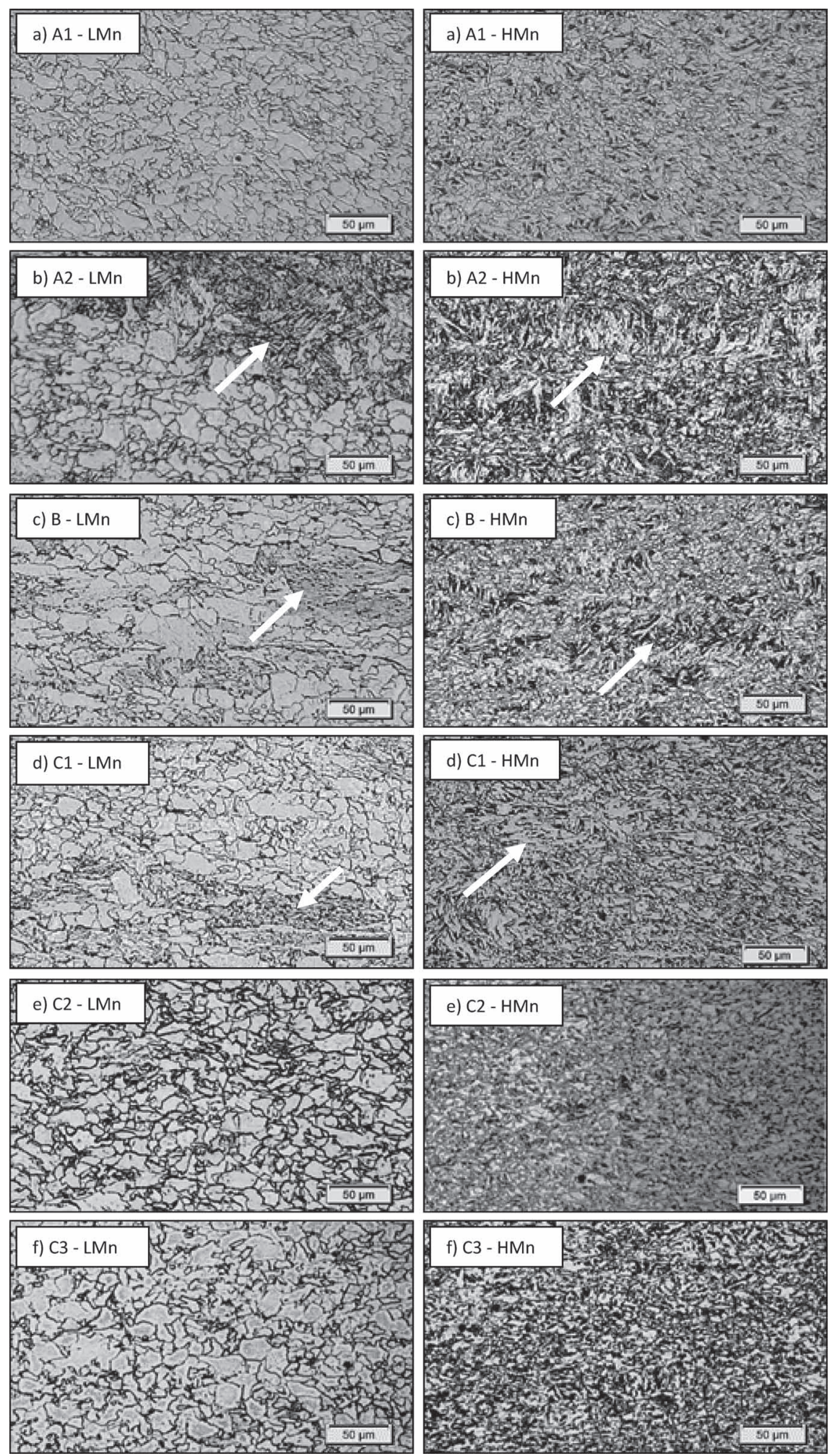

Fig. 4. "As-coiled" microstructures in $L M n$ and $H M n$ steels after schedules A-C (fig. 3). $\mathrm{F} 1=900^{\circ} \mathrm{C}$.

was calculated to be $0.047-0.06 \%$ at equalising temperatures between $1100-1125^{\circ} \mathrm{C}$, i.e., slightly less than half of the $\mathrm{Nb}$ has the potential to precipitate prior to rolling. The solute $\mathrm{Ti}$ content is close to zero in the roughing region. Coarse eutectic, plate-like $\mathrm{Nb}(\mathrm{C}, \mathrm{N})$ precipitates, similar to those observed elsewhere ${ }^{15)}$ were present, Fig. 9, which reduce the solute content available for subsequent precipitation. Eutectic precipitates were assumed not to influence roughing behaviour as they are very coarse and occur at high temperatures. Thermocalc ${ }^{\circledR}$ predicted little influence of $\mathrm{Mn}$ on $\mathrm{Nb}$ solubility in austenite in these steels. In Fig. 3 , the best-fit values between $X_{\mathrm{M}}$ and $X_{C}$ for the constant $C$ in Eq. (2) were $4.96 \times 10^{-11} \mathrm{~s}$ and $4.51 \times 10^{-11} \mathrm{~s}$ for $L M n$ and $H M n$ grades respectively, Fig. 10. The incorporation of retained strain into the effective strain after each pass was essential to obtain acceptable accuracy between $X_{\mathrm{M}}$ and $X_{C}$ values.

\subsection{Precipitation Studies}

In schedule $\mathrm{C}$, the earliest evidence of $\operatorname{NbTi}(\mathrm{C}, \mathrm{N})$ pre- 


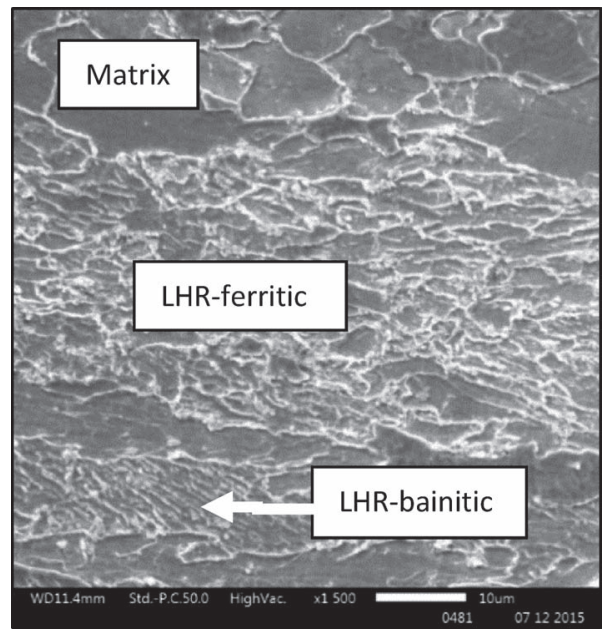

Fig. 5. SEM micrograph of LHR in "as-coiled "LMn steel. $c f$. Schedule C1.
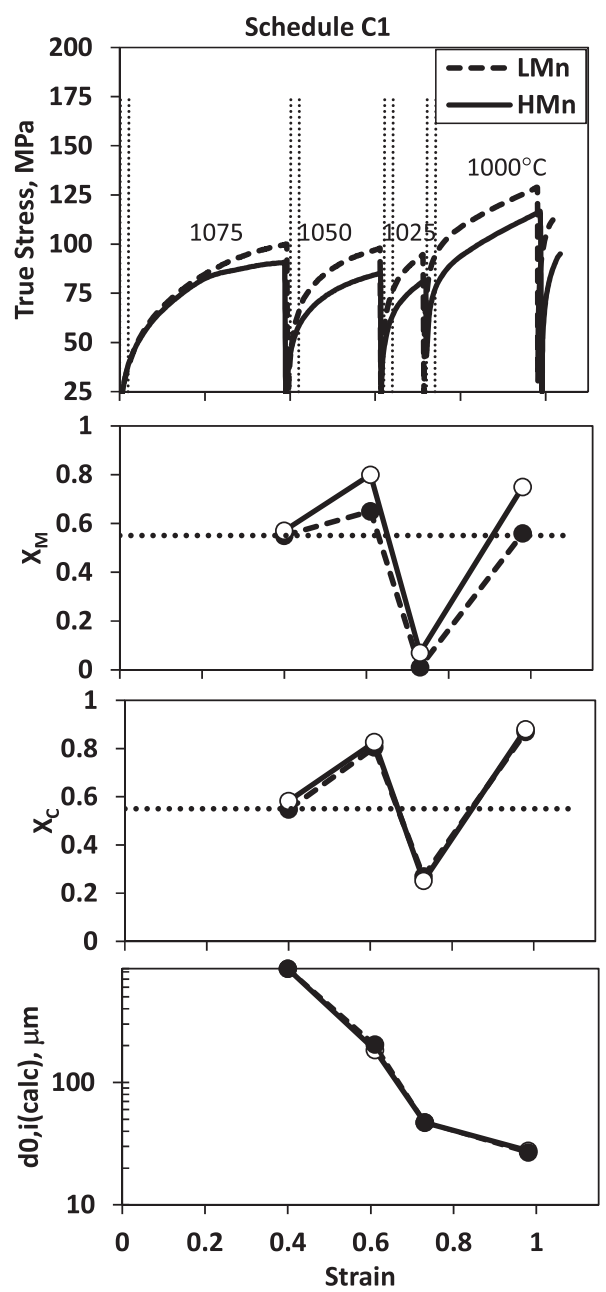

Fig. 6. Flow curves, $X$ and $d_{0, i}$ in schedule $\mathrm{C} 1$ for $\mathrm{F} 1=1000^{\circ} \mathrm{C}$.

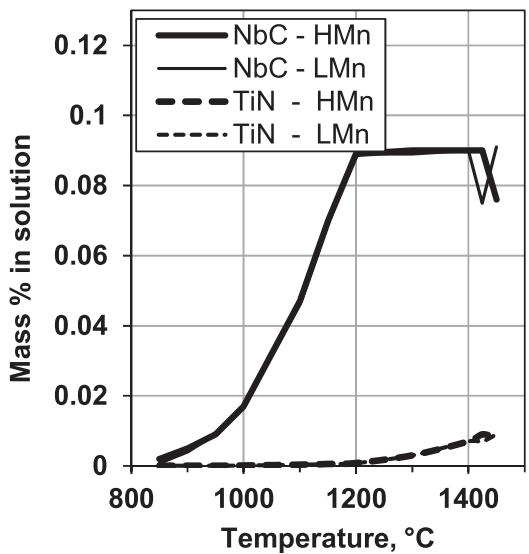

Fig. 8. $\mathrm{Nb}$ and $\mathrm{Ti}$ solute contents in $0.06 \% \mathrm{C}-0.09 \% \mathrm{Nb}-0.01 \% \mathrm{Ti}-$ $0.006 \% \mathrm{~N}$ steel as a function of temperature and $\mathrm{Mn}$ content as calculated using Thermocalc ${ }^{\mathbb{B}}$.

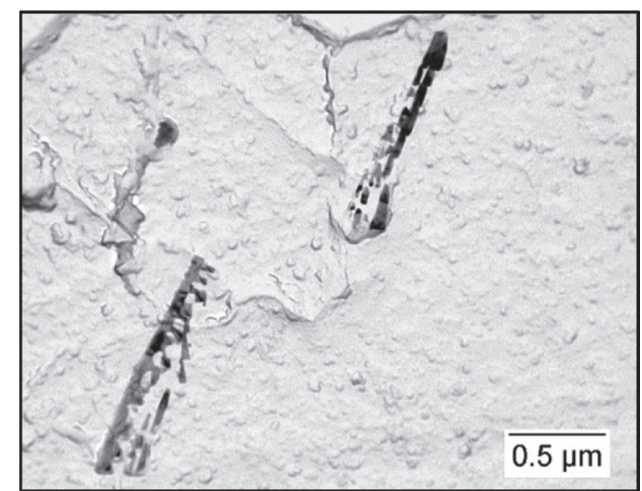

Fig. 9. TEM micrograph showing eutectic $\mathrm{Nb}$ precipitates in grade $H M n$, schedule $\mathrm{C} 1$, quenched from $1100^{\circ} \mathrm{C}$.

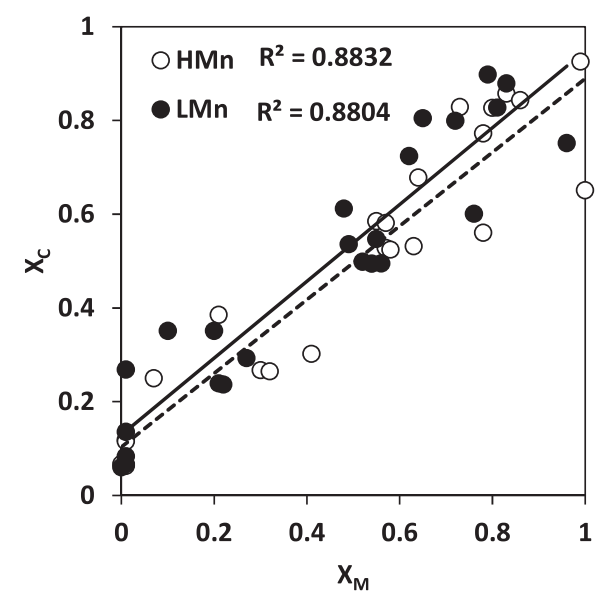

Fig. 10. Softened fraction $X$ in passes R1 and R2 - all tests. Measured vs Calculated.
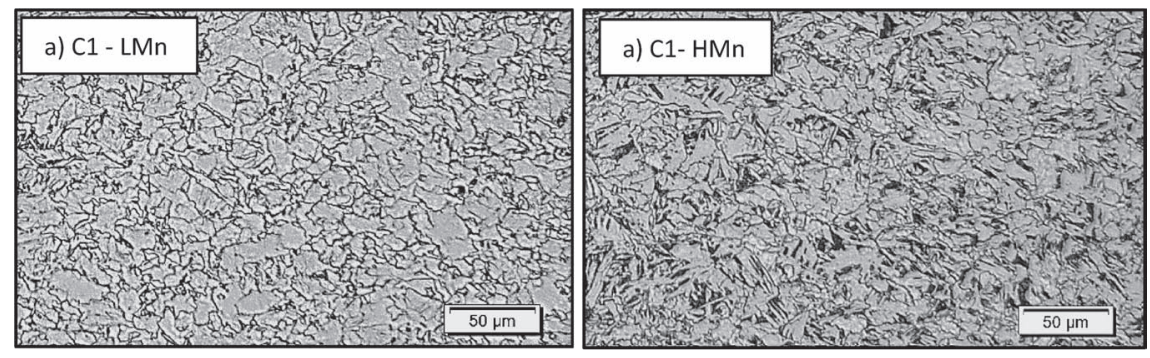

Fig. 7. "As-coiled" microstructures in $L M n$ and $H M n$ steels after schedule $\mathrm{Cl}$ (fig. 5). $\mathrm{F} 1=1000^{\circ} \mathrm{C}$. 

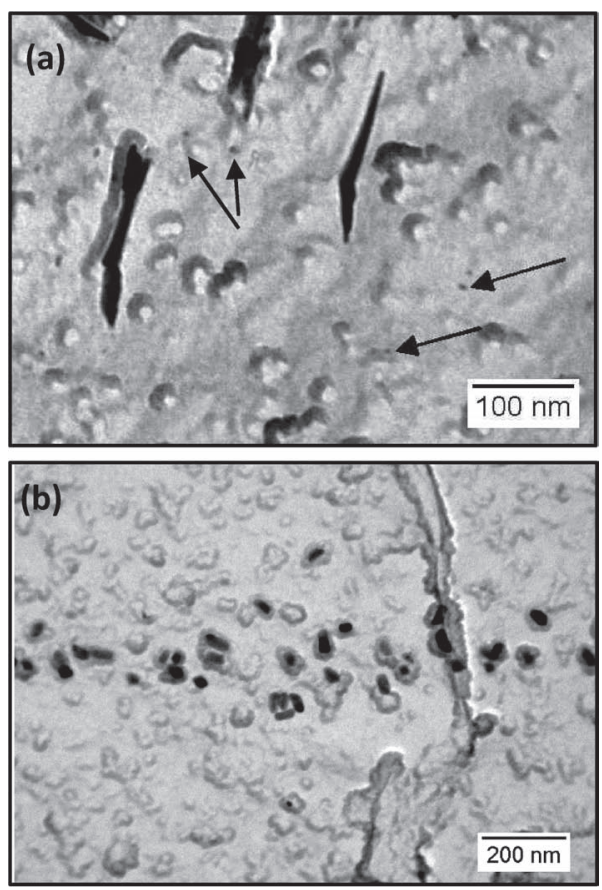

Fig. 11. TEM extraction replicas showing (a) fine (4-7 nm, arrows) matrix precipitation in $L M n$ after cooling to $T_{\min }$ from $1400^{\circ} \mathrm{C}$ and (b) Coarse, $\mathrm{Nb}, \mathrm{Ti}(\mathrm{C}, \mathrm{N})$ particles in $H M n$ after R1, schedule $\mathrm{C} 1$.
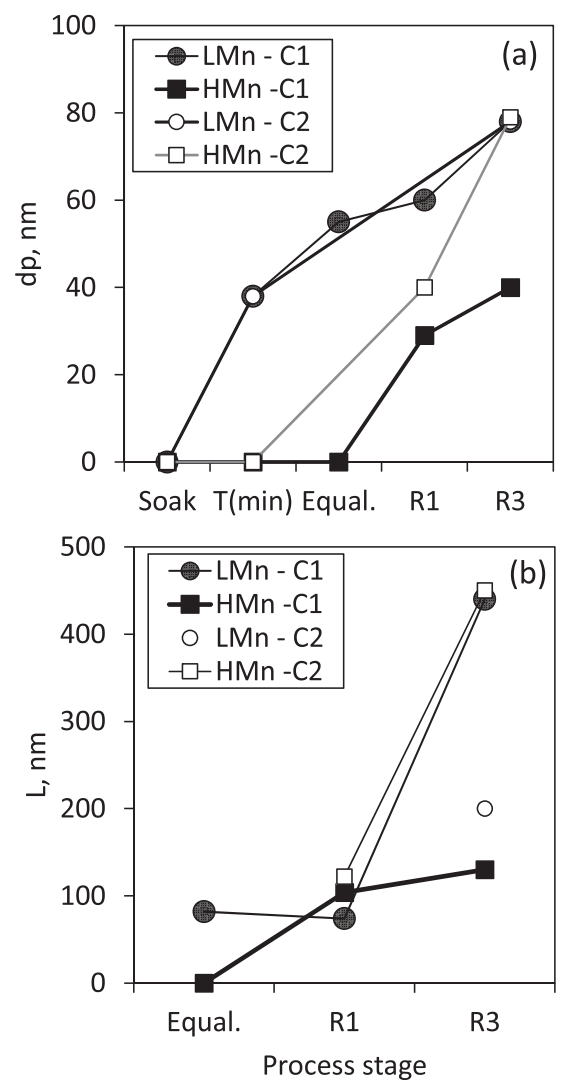

Fig. 12. Precipitate evolution in grades $L M n$ and $H M n$. (a) $d_{p}$ and (b) $L$ measurements after schedules $\mathrm{C} 1$ and $\mathrm{C} 2$.

cipitation in low Mn grade $L M n$ was found at $T_{\min }$, Fig. 2, showing that fine $(4-7 \mathrm{~nm})$, undeformed precipitation preceded roughing, Fig. 11(a). Precipitation in the $H M n$ steel was first detected after R1 in the case of schedule C1, Fig. 11(b). The $d_{p}$ and $L$ at various stages of schedules $\mathrm{C} 1$ and $\mathrm{C} 2$ are shown in Fig. 12. Figure 12(a) shows that in both $L M n$ and $H M n, d_{p}$ after R3 is above $30 \mathrm{~nm}$. Occasionally, a high density of precipitation was observed on grain boundaries, as indicated by the small $L$ values, Fig. 12(b). After $\mathrm{R} 1$, there is no evidence of $d_{p}$ smaller than $5 \mathrm{~nm}$, implying that nucleation is complete and only growth and coarsening occurred. Excluding the $\mathrm{Nb}$ eutectic phase, no precipitation was observed in either grade after direct cooling to $1100^{\circ} \mathrm{C}$.

\section{Discussion}

\subsection{Particle Evolution and Pinning Force}

Particles below $10 \mathrm{~nm}$ are generally coherent and effective for increasing flow stress, ${ }^{16)}$ retarding recovery, recrystallization and resisting dislocation motion. Fine precipitation in the 4-7 $\mathrm{nm}$ diameter range was detected prior to roughing only in $L M n$, Fig. 11(a), indicating that precipitation is more rapid compared to the $H M n$ steel.

In the HMn steel the precipitates nucleate at the onset of deformation in R1 and coarsen to $30 \mathrm{~nm}$ in the $15 \mathrm{~s}$ inter-pass time - a growth rate similar to that predicted by Manohar. ${ }^{17}$ ) However, the $d_{p}$ after R1 is generally similar to the particle sizes present prior to equalization. ${ }^{18)}$ These particles are generally incoherent and do not affect recrystallization.

The lack of influence of precipitation was confirmed in Fig. 13(a), where no clear relationship between $d_{p}$ and $X_{\mathrm{M}}$ was found. However, since large $L$ appears to increase $X$, the combined effect of $d_{p}$ and $L$ were considered by evaluating particle pinning and recrystallisation forces. The driving force for grain boundary front migration during static recrystallization is $F_{\mathrm{REX}}=\mu b^{2} \Delta \varphi / 2$ where $\mu$ is the shear modulus of austenite, $b$ is the Burgers vector, and $\Delta \varphi$ is the change in dislocation density associated with the migration of the recrystallization front into the deformed region. ${ }^{19)}$ The formation of a high volume fraction, $f$, of fine precipitation of radius, $r$, resists this force on a flexible boundary ${ }^{20)}$ by exerting an opposing force, $F_{\mathrm{PIN}}=3 \sigma f^{2 / 3} / \pi r$ where $\sigma$ is the interfacial energy per unit area of boundary. ${ }^{21)}$ The driving force for recrystallisation increases when $F_{\text {REX }}$ rises and when $F_{\text {PIN }}$ decreases. Force $-X$ plots in Fig. 13(b) for schedules $\mathrm{C} 1$ and $\mathrm{C} 2$ after pass $\mathrm{R} 1$ gave inverse relationships to those expected for both steels - i.e. higher $F_{\text {PIN }}$ increases $X$ and low $F_{\text {REX }}$ increases $X$. Thus, Nb probably influences recrystallisation in solute form since no correlations between $X$ and precipitate characteristics were found. This concurs with Kundu et al. ${ }^{22)}$ who found a stronger effect of solute drag than particle pinning in retarding recrystallisation in $\mathrm{Nb}$ steels at temperatures above $1050^{\circ} \mathrm{C}$, i.e., during roughing.

\subsection{Elimination of Local Heterogeneous Microstruc- ture}

As stated earlier, the overall, or bulk $X$ should be above 0.55 in $\mathrm{R} 1$ and in at least one other pass, whether in roughing or early finishing. Theoretically however, $X$ should approach unity to eliminate local heterogeneous regions. This disparity can, in part, be accounted for by considering the local strain distribution in both axisymmetric specimens and flat-rolled products for a given applied bulk strain. Szeliga $^{23)}$ has shown that the local strain at the work piece centre is larger than the applied strain and the difference 

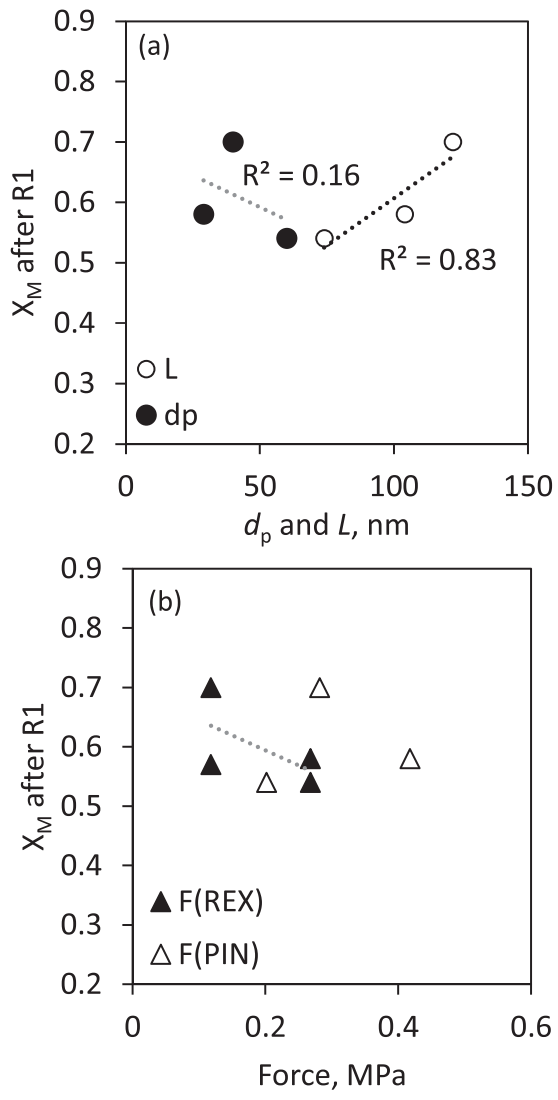

Fig. 13. (a) The influence of $d_{p}$ and $L$ on $X$ after R1 showing no relationship between $d_{\mathrm{p}}$ and $X$ but good correlation with $L$. (b) Weak relationships were found between $F_{R E X}, F_{P I N}$ and $X$ after R1 for both steels in schedules $\mathrm{C} 1$ and $\mathrm{C} 2$.

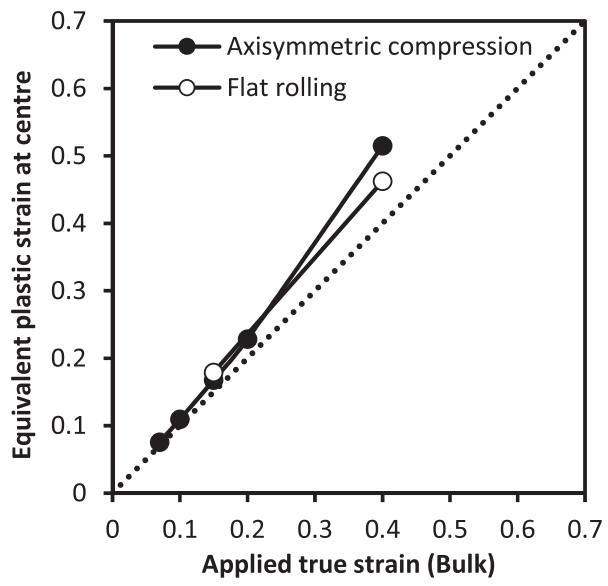

Fig. 14. FEM plot showing relationship between applied strain and centre strain (von Mises) in $5 \times 10 \mathrm{~mm}^{2}$ axisymmetric specimens and flat plate rolling. ${ }^{23)}$

between the two strains increases with applied strain, but slightly less in flat rolling. ${ }^{24)}$ This was seen after ABAQUS ver. 6.11 FEM simulations in Fig. 14. Thus, it is expected that more recrystallization and a consequent decrease in local heterogenity occurs in the central regions. For e.g. applied strains of 0.2 and 0.4 produce localised strains of 0.25 and 0.52 respectively at the specimen centre. A local strain of 0.52 in schedule $\mathrm{C} 2$ is expected to result in an $X_{\mathrm{C}}$ of 0.89 , compared to only 0.72 for a bulk strain of 0.4 . Of course, subsequent passes with high $X$ values provide additional energy to recrystallize the remaining local hetero- geneous regions. Slow air cooling after roughing provides additional time at high temperatures for more extensive SRX and MDRX.

The extent of recrystallization in R1 is critical to eliminating local heterogeneous regions. This is clearly seen in schedule B, where even a very large applied strain $(0.5)$ in $\mathrm{R} 2$, together with the retained strain from $\mathrm{R} 1$, provided a local central strain approaching 0.75 but does not eliminate local heterogeneous regions, despite the initiation of MDRX which is a more potent grain refining process than SRX. This is attributed to insufficient subsequent deformation for the so-called "necklacing" process to go to completion at coarse austenite grain boundaries inherited from R1.

It is not clear why the extent of softening in R1 is so high $\left(X_{\mathrm{M}}>0.75\right)$ in both grades after direct cooling to the equalising temperature of $1100^{\circ} \mathrm{C}$ in schedule $\mathrm{C} 3$, given the same $d_{0}$ as in schedules $\mathrm{C} 1$ and $\mathrm{C} 2$. A possible explanation is more homogeneous distribution of solute in the absence of grain boundary precipitation prior to R1 may facilitate easier recrystallisation.

Slow air cooling to a high $\mathrm{F} 1$ temperature of $1000^{\circ} \mathrm{C}$ contributes to more extensive static recrystallisation which aids the elimination of local heterogenous regions. However, care must be taken if this route is adopted in the processing of thick HTP steels, since high temperature processing in the partial recrystallisation region may produce mixed final structures which compromises the final properties.

The cooling conditions after rolling may also be a determining factor regarding the presence of local heterogenous regions. In Fig. 5, ferritic and bainitic local heterogenous regions morphologies were identified. Whilst a fine local heterogenous region with ferrite microstructure may not affect, or indeed improve properties, a high hardenability (due to the large prior austenite grain size compared to the matrix), coupled with sufficiently fast cooling rates, can instead transform the local heterogenous regions to a low temperature transformation product, such as bainite, and impair toughness because the effective grain size of a local heterogenous region now becomes that of the coarse prior austenite grain.

\subsection{Influence of $\mathrm{Mn}$}

The lower $X_{\mathrm{M}}$ values found in the LMn grade at roughing temperatures indicates slower recrystallization kinetics in low Mn steels. Akben et al. ${ }^{7)}$ found that when $\mathrm{Mn}$ is added to $0.035 \% \mathrm{Nb}$ steel, the solubility of the carbonitride is increased, so that the rate and amount of precipitation at a given temperature and strain are decreased. Both higher $\mathrm{Nb}$ and increased $\mathrm{Mn}$ in solution contribute to the retardation of the softening processes. When Mn (or V, Mo) is added to a $\mathrm{Nb}$ steel, the activity coefficient of $\mathrm{Nb}$ increases but decreases those of $\mathrm{C}$ and $\mathrm{N}$ appreciably, producing a net retardation of precipitation and recovery. ${ }^{7)}$ Zurob et al. ${ }^{8)}$ found that low $\mathrm{Mn}$ is better at preventing static recrystallisation than high $\mathrm{Mn}$ steel, i.e., strain accumulation is more pronounced in low Mn steels. Whilst these effects are desirable during finishing for austenite pancaking, it is harmful in roughing, where the prevention of recrystallization from going to completion promotes local heterogenous microstructure, particularly in coarse-grained as-cast austenite subjected to small/intermediate strains. The larger austenite 
grain size in the low Mn steel during roughing, as suggested by the occasional bainitic morphology of "as-coiled" local heterogenous regions (the larger grain size providing greater hardenability), may also contribute to the slower recrystallisation kinetics in the $L M n$ grade.

The HMn steel was expected to display higher flow stresses during roughing and early finishing. However, the stress magnitudes in the $L M n$ grade were comparable to, and sometimes higher than, that observed in the HMn grade. An explanation for the relatively high deformation resistance in grade $L M n$ is the potential formation of clusters, not precipitates, when solutes concentrations are low, i.e. low Mn, which will retard recovery in worked austenite and increase flow stress. ${ }^{7)}$

\section{Conclusions}

Roughing conditions necessary to avoid the formation of local heterogeneous regions have been established for HTP steels with an initial grain size of $850 \mu \mathrm{m}$. The following are concluded:

(1) Low $\mathrm{Mn} \mathrm{Nb-Ti} \mathrm{steels} \mathrm{experience} \mathrm{more} \mathrm{sluggish}$ recrystallisation kinetics and are more vulnerable to forming local heterogeneous regions during roughing.

(2) To prevent local heterogenous microstructure if finishing commences at $900^{\circ} \mathrm{C}$, sufficient effective strain is necessary to produce a bulk softened fraction of at least 0.55 in each of the first two roughing passes. If finishing commences at $1000^{\circ} \mathrm{C}$, slow air cooling from roughing provides additional time for recrystallisation to go to completion and so prevent the occurrence of local heterogenous regions.

(3) Maintaining the strand temperature as high as possible prior to the commencement of roughing encourages recrystallisation. A roughing start temperature of $1100^{\circ} \mathrm{C}$, as opposed to $1075^{\circ} \mathrm{C}$, significantly reduces the risk of forming local heterogenous regions.

(4) For the conditions tested, no correlation between softening fraction and carbonitride precipitate characteristics was found. Thus, the influence of $\mathrm{Nb}$ on austenite recrystallisation is expected to be due to either solute drag or solute clustering.

\section{Acknowledgements}

The authors are grateful to CBMM and Dr. Malcolm Gray of the Microalloyed Institute for financial support.

\section{REFERENCES}

1) K. M. Banks and R. Maubane: Proc. Advanced Steel Metallurgy: Products and Processing, MS\&T14, TMS, Warrendale, PA, (2014), 453.

2) M. Imagumbai and H. Takechi: Proc. Int. Conf. on Processing and Manufacturing of Advanced Materials (Thermec 2003), eds. by T. Chandra et al., Trans Tech Publications, Zurich, (2003), 426.

3) K. M. Banks and R. Maubane: Conf. Proc. HSLA Steel 2015, Microalloying 2015 and Offshore Engineering, Steels 2015, Chinese Society for Metals and Chinese Academy of Engineering, Beijing, (2015), 783.

4) P. Uranga, A. I. Fernández, B. López and J. M. Rodriguez-Ibabe: ISIJ Int., 44 (2004), 1416.

5) Y. Sha, Z. Q. Sun and L. F. Li: Ironmaking Steelmaking, 42 (2015), No. 1,74 .

6) J. M. Gray and F. Barbarro: Conf. Proc. HSLA Steel 2015, Microalloying 2015 and Offshore Engineering Steels 2015, Chinese Society for Metals and Chinese Academy of Engineering, Beijing, (2015), 53.

7) M. G. Akben, B. Bacroix and J. J. Jonas: Acta Metall., 31 (1983), 161.

8) H. S. Zurob, G. Zhu, S. V. Subramanian, G. R. Purdy, C. R. Hutchinson and Y. Brechet: ISIJ Int., 45 (2005), 713.

9) A. I. Fernández, P. Uranga, B. López and J. M. Rodriguez-Ibabe: ISIJ Int., 40 (2000), 893.

10) P. Uranga, A. I. Fernández, B. López and J. M. Rodriguez-Ibabe: Mater. Sci. Eng. A, 345A (2003), 319.

11) R. Abad, A. I. Fernández, B. López and J. M. Rodriguez-Ibabe: ISIJ Int., 41 (2001), 1375.

12) C. Roucoules, S. Yue and J. J. Jonas: Metall. Mater. Trans. A, 26A (1995), 181

13) P. Uranga, A. I. Fernández, B. López and J. M. Rodriguez-Ibabe: Proc. 44th MWSP Conf., Vol. 40, ISS, Warrendale, PA, (2002), 945.

14) F. Siciliano and J. J. Jonas: Metall. Mater. Trans. A, 31A (2000), 511.

15) O. Hunderi and N. Ryum: Acta Metall. Mater., 40 (1992), 543.

16) T. Greday and M. Lamberigts: Proc. Conf. Microalloying ' 75 , Union Carbide Corporation, New York, (1977), 172.

17) P. A. Manohar, D. P. Dunne, T. Chandra and C. R. Killmore: ISIJ Int., 36 (1996), 194.

18) A. Ruiz-Aparicio: MSc Dissertation, University of Pittsburgh, (2004), http://d-scholarship.pitt.edu/7913/1/ARTURORUIZAPARICIO.pdf, (accessed 2015-09-02).

19) U. F. Kocks, A. S. Argon and M. F. Ashby: Progress in Materials Science, Vol. 19, ed. by B. Chalmers, Pergamon Press, Oxford, (1975), 1.

20) E. J. Palmiere, C. I. Garcia and A. J. DeArdo: Metall. Mater. Trans. A, 27A (1996), 951.

21) L. Cuddy: Thermomechanical Proc. Microalloyed Austenite, eds. by A. J. DeArdo, et al., TMS-AIME, Warrendale, PA, (1982), 129.

22) A. Kundu: Ph.D. thesis, The University of Birmingham, (UK), (2011), https://core.ac.uk/download/files/121/1631723.pdf, (accessed 201511-03).

$23)$ D. Szeliga, R. Kuziak, R. Kopp, G. Smyk and M. Pietrzyk: Arch. Metall. Mater., 60 (2015), No. 4, 3087.

24) M. Pietryzyk and J. G. Lenard: Thermal-Mechanical Modelling of the Flat Rolling Process, MRE, eds. by B. Ilschner and N. J. Grant, Springer-Verlag, Berlin, Heidelberg, (1991), 161. 